 \\ Respiratory and Pulmonary Medicine
}

RESEARCH ARTICLE

\section{Association between Cigarette Smoking and Serum Gamma-Glu- tamyl Transferase Level}

\author{
Dongcheol Lee, Hyun Wuk Kang and Yu II Kim* \\ Department of Internal Medicine, Chonnam National University Hospital, South Korea
}

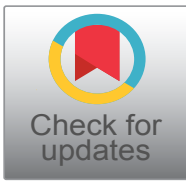

*Corresponding author: Yu II Kim, MD, Department of Internal Medicine, Chonnam National University Hospital, Gwangju, South Korea, Tel: +82-62-220-6296, Fax: +82-62-225-8578

\begin{abstract}
Background: Gamma-glutamyltransferase (GGT) is an enzyme mainly produced from the cells of the hepatobiliary tract. And, it has been introduced as a biomarker for oxidative stress mainly by alcohol consumption and current smoking. This study was performed to evaluate the association between smoking status and serum GGT concentration.

Methods: The effect of cigarette smoking on serum activities of the enzyme, GGT was investigated using the data of the $5^{\text {th }}$ Korea National Health and Nutrition Examination Survey ( $5^{\text {th }}$ KNHANES, 2010 to 2012); a cross sectional survey in the general population of Korea.

Results: The author analyzed 11,849 subjects (age $\geqq 19$ years) who had the data about smoking status and serum GGT levels. Subjects comprised 4,881 subjects who are cigarette smokers and 6,968 who do not smoke, which serves as control. The mean \pm standard deviation (S.D) of serum GGT levels in non-smokers, current and former smokers were $23.18 \pm 24.03 \mathrm{U} / \mathrm{L}, 52.69 \pm 73.21 \mathrm{U} / \mathrm{L} 41.63 \pm 58.48 \mathrm{U} / \mathrm{L}$ and respectively, showing a significant increase in serum level of GGT $(P<0.001)$ in smokers when compared with controls. GGT levels showed a significant positive correlation with amount of smoking $(r=0.249, P<0.001)$. Cigarette smoking produced a significant increase in GGT activity irrespective of low to moderate alcohol consumption in the multivariate regression analyses.
\end{abstract}

Conclusion: Former smoking as well as current smoking can be related to the elevation of serum GGT concentration. And, the amount of smoking has a significant relation with serum GGT concentration irrespective of alcohol consumption. Former smoking with the amount of smoking should be taken into account when assessing the significance of GGT activities.

\section{Keywords}

Cigarette smoking, Former smoking, Amount of smoking Serum Gamma-glutamyl transferase

\section{Introduction}

Gamma-glutamyltransferase (GGT) is an enzyme mainly produced from the cells of the hepatobiliary tract. Whereas alcohol consumption certainly remains the single most prominent GGT predictor, significant associations with additional modifiable factors such as body mass index (BMI), coffee consumption and smoking have been shown repeatedly [1-3]. It has also been introduced as a biomarker for oxidative stress [4] by smoking as well as alcohol consumption [3,5-9]. It is an emergent risk marker for a variety of common diseases such as diabetes and cancer $[10,11]$, as well as for overall and cause-specific mortality [12]. Better understanding of factors determining individual GGT levels thus has become a quest of high relevance to public health. However, there have not been many studies evaluating the relationship of GGT levels with former smoking and it is still not clear whether the effect is independent of alcohol drinking.

This study was performed to evaluate the association between smoking status and serum GGT concentration using the fifth Korean National Health and Nutrition Examination Survey ( $5^{\text {th }}$ KNHANES, 2010 to 2012) data.

\section{Materials and Methods}

\section{Participants}

The KNHANES [13] is an ongoing surveillance system in the Republic of Korea that assesses the health and nutritional status of Koreans, monitors trends in health risk factors and the prevalence of major chronic diseas- 
es and provides data for the development and evaluation of health policies and programs in the general population of Korea. It has been conducted periodically by the Korea Centers for Disease Control and Prevention since 1998 in 600 national districts in Korea.

KNHANES data (V, $2010 \sim 2012$ ) samplings containing serum GGT data were used in this cross-sectional analysis. From an initial total of 25,534 men and women (Figure 1), those younger subjects than 19-years-old (5,935 subjects) were also excluded. Also, 7,750 people were excluded due to missing data (the missing data of serum GGT, 7,745 subjects; smoking data missing, 5 subjects). In total, 11,849 subjects were included in this analysis.

\section{Smoking status}

Behavioral Risk Factor Surveillance System respondents were asked: "Have you smoked at least 100 cigarettes in your entire life?" and "Do you now smoke cigarettes every day, some days, or not at all?" Responses were grouped into three categories: Current Smoker, Former Smoker, and Never Smoker. Respondents who reported smoking at least 100 cigarettes in their lifetime and who, at the time of survey, smoked either every day or some days were defined as Current Smoker. Respondents who reported smoking at least 100 cigarettes in their lifetime and who, at the time of the survey, did not smoke at all were defined as Former Smoker. Respondents who reported never having smoked 100 cigarettes were defined as Never Smoker. Pack year is cal- culated by multiplying the number of packs of cigarettes smoked per day by the number of years the person has smoked.

\section{Measurements}

Serum GGT concentration (Unit/L) was assayed by the standard method recommended by the International Federation for Clinical Chemistry using pure auto GGT as substrate with a Hitachi Automatic Analyzer 7600 (Hitachi Co., Tokyo, Japan). A self-administered questionnaire of smoking status and alcohol intake were used as describe before [13]. Body mass index (BMI) was calculated as weight ( $\mathrm{kg}$ ) divided by height squared $\left(\mathrm{m}^{2}\right)$.

\section{Statistical analysis}

Complex sample analysis was used for KNHANES-V data for weighting all values following the guidance on statistics from the Korea Centers for Disease Control and Prevention. Initially, the author used a simple descriptive analysis for general characteristics such as age, $\mathrm{BMI}$, and sex.

The author examined the associations of smoking status with serum GGT not considering the possible interaction between GGT and other confounding factors. Next, Analyses were adjusted for age, sex, BMI, alcohol consumption (daily alcohol intake amount), smoking status (current smoker, former smoker, or never smoker), pack-years of cigarette smoking.

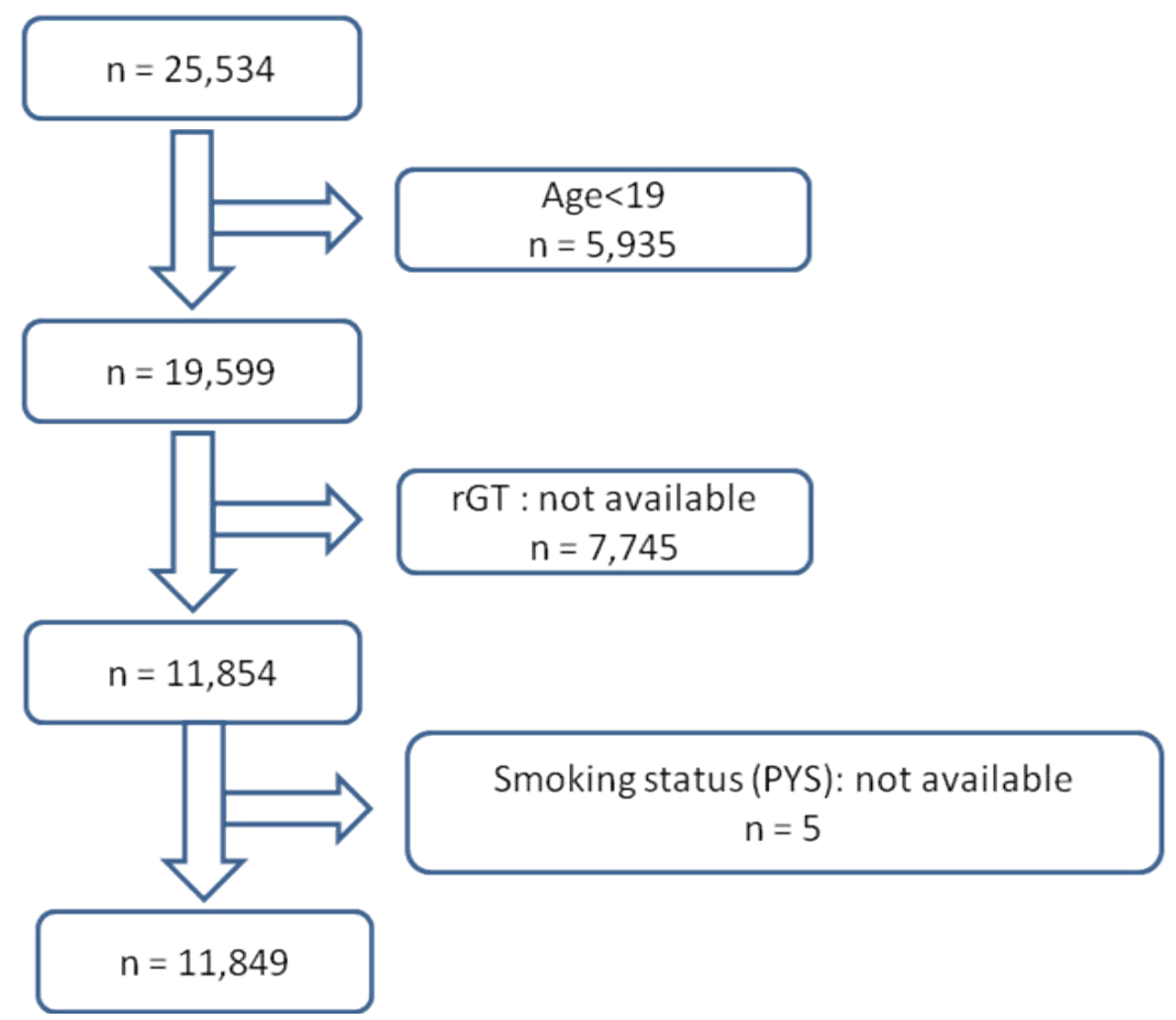

Figure 1: Consort diagram of the study participants. 
Pearson's correlation analysis was performed to evaluate the association between smoking amount (Pack $\times$ Years, PYs) and serum GGT concentration.

$P<0.05$ was considered significant. Data were analyzed using SPSS ver. 21.0 (IBM, USA).

\section{Results}

The author analyzed 11,849 subjects (age $\geqq 19$ years) who had the data about smoking status and serum GGT levels. Subjects comprised 4,881 subjects who are cigarette smokers and 6,968 who do not smoke, which serves as control (Figure 1 and Table 1). Most of female subjects were never smokers $(89.0 \%)$ while male subjects were current $(41.4 \%)$ or former smokers (39.5\%). Smokers had more frequent drinking of alcohol and more amount of alcohol drinking compared to con-

Table 1: Characteristics of Subjects by smoking status.

\begin{tabular}{|c|c|c|c|c|c|c|}
\hline & & & $\begin{array}{l}\text { Never smoker } \\
(n=6968)\end{array}$ & $\begin{array}{l}\text { Current smoker } \\
(n=2481)\end{array}$ & $\begin{array}{l}\text { Ex-smoker } \\
(n=2400)\end{array}$ & $p$ value \\
\hline Age & & (yrs, mean) & 49.61 & 45.87 & 54.15 & $<0.001$ \\
\hline BMI & & $\left(\mathrm{kg} / \mathrm{m}^{2}\right.$, mean $)$ & 23.45 & 23.74 & 24.01 & $<0.001$ \\
\hline \multirow[t]{4}{*}{ Sex } & \multirow[t]{2}{*}{ Female } & $\mathrm{n}$ & 5990 & 362 & 376 & \multirow[t]{2}{*}{$<0.001$} \\
\hline & & $(\%)$ & $89.00 \%$ & $5.40 \%$ & $5.60 \%$ & \\
\hline & \multirow[t]{2}{*}{ Male } & $\mathrm{n}$ & 978 & 2119 & 2024 & \multirow[t]{2}{*}{$<0.001$} \\
\hline & & $(\%)$ & $19.10 \%$ & $41.40 \%$ & $39.50 \%$ & \\
\hline \multirow{4}{*}{$\begin{array}{l}\text { Frequency of alcohol } \\
\text { drinking (times/ } \\
\text { month) }\end{array}$} & \multirow[t]{2}{*}{$<2$} & $\mathrm{n}$ & 3531 & 585 & 840 & \multirow[t]{2}{*}{$<0.001$} \\
\hline & & $(\%)$ & $71.20 \%$ & $11.80 \%$ & $16.90 \%$ & \\
\hline & \multirow[t]{2}{*}{$\geqq 2$} & $\mathrm{n}$ & 1867 & 1798 & 1422 & \multirow[t]{2}{*}{$<0.001$} \\
\hline & & $(\%)$ & $36.70 \%$ & $35.30 \%$ & $28.00 \%$ & \\
\hline \multirow{4}{*}{$\begin{array}{l}\text { Amount of alcohol } \\
\text { drinking (glasses/ } \\
\text { drinking) }\end{array}$} & \multirow[t]{2}{*}{$<5$} & $\mathrm{n}$ & 3470 & 703 & 974 & \multirow[t]{2}{*}{$<0.001$} \\
\hline & & $(\%)$ & $67.40 \%$ & $13.70 \%$ & $18.90 \%$ & \\
\hline & \multirow[t]{2}{*}{$\geqq 2$} & $\mathrm{n}$ & 948 & 1522 & 947 & \multirow[t]{2}{*}{$<0.001$} \\
\hline & & $(\%)$ & $27.70 \%$ & $44.50 \%$ & $27.70 \%$ & \\
\hline Amount of smoking & & PYs, mean & 0 & 19.73 & 17.76 & $<0.001$ \\
\hline
\end{tabular}

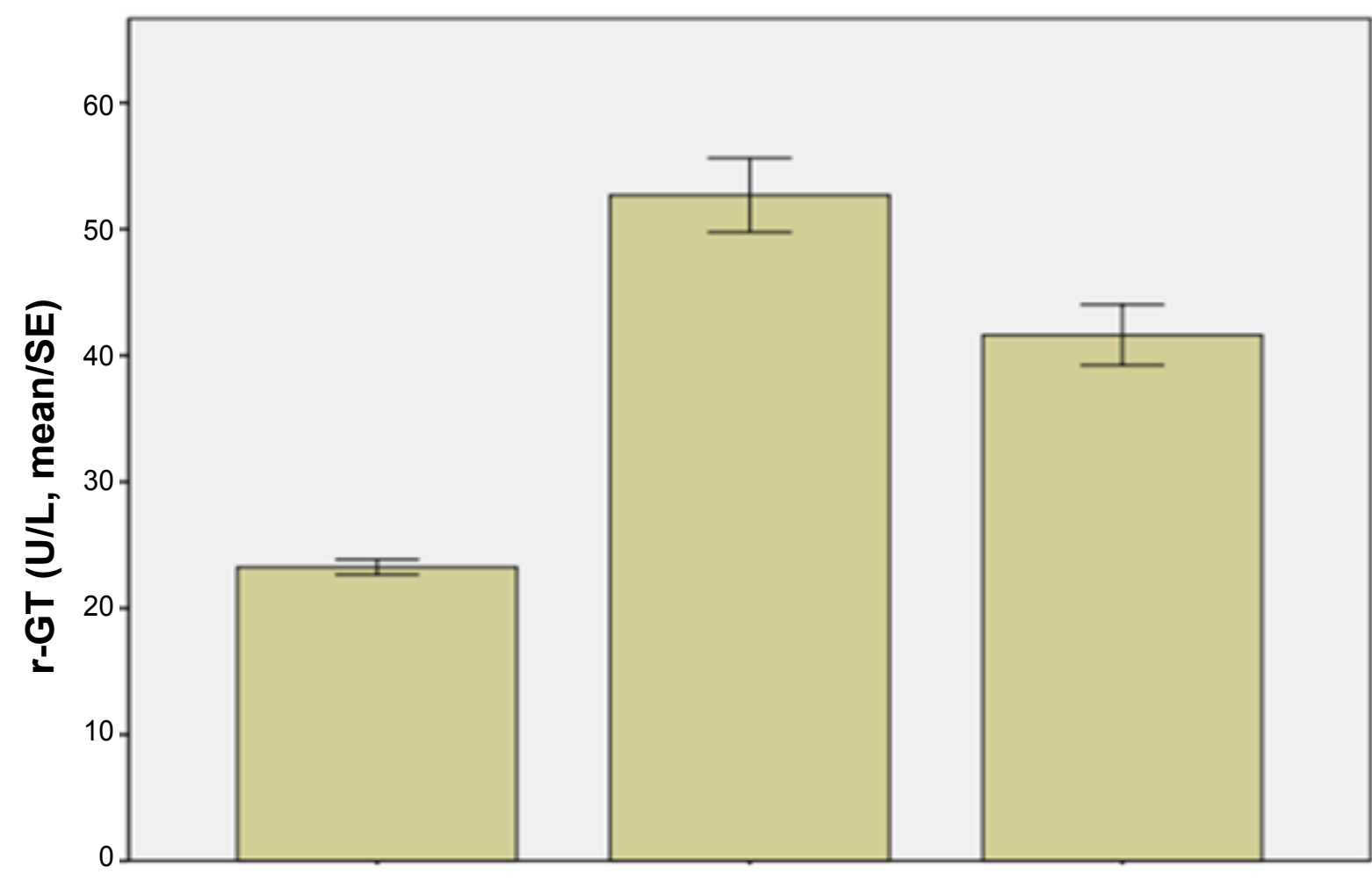

Never smoker Current smoker Ex-smoker

Figure 2: Serum GGT levels by smoking status. 
Table 2: Associated factors for serum GGT levels in the multivariate analysis.

\begin{tabular}{|l|l|l|l|l|l|}
\hline & B & Std. E & beta & T & p value \\
\hline Age & 0.327 & 0.041 & 0.092 & 7.884 & $<0.001$ \\
\hline Sex (M) & 12.139 & 1.426 & 0.111 & 8.513 & $<0.001$ \\
\hline BMI & 1.44 & 0.17 & 0.088 & 8.493 & $<0.001$ \\
\hline PYs_current smoker & 0.664 & 0.056 & 0.141 & 11.877 & $<0.001$ \\
\hline PYs_exsmoker & 0.251 & 0.055 & 0.053 & 4.539 & $<0.001$ \\
\hline Frequency of drinking (> 2/Mo.) & 8.449 & 1.297 & 0.076 & 6.512 & $<0.001$ \\
\hline Amount of drinking (> 5 glasses/drinking) & 12.452 & 1.408 & 0.112 & 8.843 & $<0.001$ \\
\hline & & & & $\left(r^{2}=0.132, p<0.001\right)$ \\
\hline
\end{tabular}

trols (Table 1 ).

The mean \pm standard deviation (S.D) of serum GGT levels in non-smokers, current and former smokers were $23.18 \pm 24.03 \mathrm{U} / \mathrm{L}, 52.69 \pm 73.21 \mathrm{U} / \mathrm{L} 41.63 \pm 58.48$ $\mathrm{U} / \mathrm{L}$ and respectively, showing a significant increase in serum level of GGT $(P<0.001)$ in smokers when compared with controls (Figure 2).

In multivariate analysis including the variables ( $\mathrm{Ta}$ ble 2), PYs by smoking status (current and ex-smoker), age, sex, and frequency and amount of alcohol drinking showed consistent and significant associations with GGT levels. Amount of smoking was positively associated with serum GGT levels in both smokers, current and former smokers $(p<0.001)$ (Table 2).

GGT levels showed a significant positive correlation with amount of smoking $(r=0.249, P<0.001)$ in the Pearson's correlation analyses.

\section{Discussion}

The present study demonstrated that data from KNHANES-V showed that former cigarette smoking as well as current smoking produced a significant increase in GGT activity. And, the amount of smoking (PYs) has a significant relation with serum GGT concentration irrespective of alcohol consumption. Former smoking and amount of smoking (PYs) should be taken into account when assessing the significance of GGT activities.

Traditionally, serum GGT activity has been used as a marker for excessive alcohol consumption or liver diseases in clinical practice. A dose response relationship is generally seen in which the mean GGT increases as the amount of self-reported alcohol consumption increases [14]. Elevated GGT levels may be induced by glutathione depletion and oxidative stress resulting from alcohol consumption [2].

Recently, it has been suggested that smoking increases GGT and boosts the alcohol-induced GGT elevation [8]. Oxidative stress in the liver caused by consumption and metabolism of alcohol reaches some critical level much more easily in the presence of generalized oxidative stress caused by concurrent smoking [8]. Although smoking does not damage hepatocytes directly, it may change the effect of alcohol drinking on AST, ALT and GGT activities via the actions of numerous ingredients that alter the activities of enzymes found in the liver [15]. However, there have not been many studies evaluating the relationship of GGT levels with former smoking and it is still not clear whether the effect is independent of alcohol drinking. The present study is the first study with the biggest sample size to describe an effect of former smoking on GGT. Previous studies with a relatively small sample size showed that current smokers revealed high GGT compared to non-smokers [16] or people with high GGT levels smoked more [17].

Cigarette smoke have many kinds of heavy metals such as lead, cadmium, and mercury [18]. In a lead exposure study, values of liver function test were significantly higher in industrial workers who had significantly higher mean blood lead concentration than non-industrial workers. These results might be related to environmental or smoking related lead exposure, and liver function might have been affected [19].

In a cadmium toxicity study, cadmium caused oxidative stress, mainly because it has a great affinity for thiols, especially GSH, which is the most important antioxidant in aerobic organisms [20]. Some studies show serum GGT activity increased in response to cadmium loading [21]. In cadmium exposure, diet is the main source of environmental cadmium exposure. Tobacco smoking results in 4 to 7 times higher blood cadmium in smokers than in nonsmokers [22]. Serum cadmium concentration is an independent factor with regard to higher serum GGT concentration [23].

Also, serum mercury accumulation may have been related with serum GGT elevation [23].

Heavy metal intoxication by smoking may result in oxidative stress [23]. Some studies suggest that serum GGT concentration within its normal laboratory range might be an early and sensitive marker for oxidative stress [4]. Therefore, serum GGT elevation associated with smoking might be interpreted as a reflection of oxidative stress as ethanol consumption increased the production of reactive oxygen species [24]. There is evidence that cellular GGT plays an important role in antioxidant defense systems [25]. GGT is widely distributed in the human body and is frequently localized in the plasma membrane with its active site directed into 
the extracellular space. In addition, the primary role of GGT is to metabolize extracellular reduced glutathione (GSH), allowing for precursor amino acids to be assimilated and reutilized for intracellular GSH synthesis. Thus, serum GGT acts as a cellular supply of GSH, the most important non-protein antioxidant of the cell. According to a recent study, ectoplasmic GGT may also be involved in the generation of harmful metal-induced reactive oxygen species [26]. In addition, in many animal studies, metal-induced oxidative stress can affect biologic lab data, including GGT [27].

Former smoking also can accumulate heavy metals in our body [28] that cause oxidative stress with elevation of GGT. However, in our study results, it is hard to conclude this causal relationship between serum GGT concentration and heavy metals by smoking because there is no prospective data in KNHANES. For the confirmation of the direct effect of smoking on GGT, a prospective study will be needed.

This study has several limitations. First, the author cannot draw the direct causality between serum GGT concentration and smoking because KNHANES data came from a cross-sectional design not from a prospective study as mentioned above. Second, the author could not adjust for all confounders such as coffee consumption, occupational exposure, and medical illness (liver diseases, cancer, and rheumatoid disease) that could affect the GGT levels. However, the strength of this study is the large scale and that data were representative of the general population of Korea. In addition, this is the first study to deal with former smoking and serum GGT concentration in the Korean population.

\section{Conclusion}

In conclusion, the elevation of serum GGT concentration may be related to the former smoking as well as current smoking. In particular, serum GGT showed significant correlation with amount of smoking, PYs. Former smoking should be taken into account when assessing the significance of GGT activities.

\section{References}

1. Sillanaukee $P$, Massot N, Jousilahti $P$, Vartiainen E, Sundvall J, et al. (2000) Dose response of laboratory markers to alcohol consumption in a general population. Am J Epidemiol 152: 747-751.

2. Poikolainen K, Vartiainen E (1997) Determinants of gamma-glutamyltransferase: Positive interaction with alcohol and body mass index, negative association with coffee. Am J Epidemiol 146: 1019-1024.

3. Breitling LP, Arndt V, Drath C, Rothenbacher D, Brenner $H$ (2010) Smoking and gamma-glutamyltransferase: Opposite interactions with alcohol consumption and body mass index. PLoS One: e13116.

4. Lee DH, Blomhoff R, Jacobs DR Jr (2004) Is serum gamma glutamyltransferase a marker of oxidative stress? Free Radic Res 38: 535-539.
5. Conigrave KM, Davies P, Haber P, Whitfield JB (2003) Traditional markers of excessive alcohol use. Addiction 98: 31-43.

6. Kim HW, Lee SH, Lee DH (2014) Relationship of serum gamma-glutamyltransferase levels with pulmonary function and chronic obstructive pulmonary disease. Lung 192: 719727.

7. Kim ES, Moon S, Han JH, Kim SA, Lee EH, et al. (2012) Association between serum gamma-glutamyltransferase and pulmonary dysfunction. Clin Chem Lab Med 50: 20532055.

8. Breitling LP, Raum E, Muller H, Rothenbacher D, Brenner H (2009) Synergism between smoking and alcohol consumption with respect to serum gamma-glutamyltransferase. Hepatology 49: 802-808.

9. Sharp DS, Benowitz NL (1995) Re: "Alcohol, smoking, coffee, and cirrhosis" and "coffee and serum gamma-glutamyltransferase: A study of self-defense officials in Japan". Am J Epidemiol 141: 480-482.

10. Bidel S, Silventoinen K, Hu G, Lee DH, Kaprio J, et al. (2008) Coffee consumption, serum gamma glutamyltransferase and risk of type II diabetes. Eur J Clin Nutr 62: 178-185.

11. Strasak AM, Rapp K, Brant LJ, Hilbe W, Gregory M, et al. (2008) Association of gamma-glutamyltransferase and risk of cancer incidence in men: A prospective study. Cancer Res 68: 3970-3977.

12. Kazemi-Shirazi L, Endler G, Winkler S, Schickbauer T, Wagner O, et al. (2007) Gamma glutamyltransferase and long-term survival: Is it just the liver? Clin Chem 53: 940946.

13. Kweon S, Kim Y, Jang MJ, Kim Y, Kim K, et al. (2014) Data resource profile: The Korea National Health and Nutrition Examination Survey (KNHANES). Int J Epidemiol 43: 69-77.

14. Teschke R, Brand A, Strohmeyer G (1977) Induction of hepatic microsomal gamma-glutamyltransferase activity following chronic alcohol consumption. Biochem Biophys Res Commun 75: 718-724.

15. Gordon T (1993) Factors associated with serum alkaline phosphatase level. Arch Pathol Lab Med 117: 187-190.

16. Steffensen FH, Sorensen HT, Brock A, Vilstrup $H$, Lauritzen T (1997) Alcohol consumption and serum liver-derived enzymes in a Danish population aged $30-50$ years. Int $\mathrm{J}$ Epidemiol 26: 92-99.

17. Lee DH, Lim JS, Yang JH, Ha MH, Jacobs DR Jr (2005) Serum gamma-glutamyltransferase within its normal range predicts a chronic elevation of alanine aminotransferase: A four year follow-up study. Free Radic Res 39: 589-593.

18. Galazyn-sidorczuk M, Brzoska MM, Moniuszko-jakoniuk J (2008) Estimation of polish cigarettes contamination with cadmium and lead, and exposure to these metals via smoking. Environ Monit Assess 137: 481-493.

19. Al-Neamy FR, Almehdi AM, Alwash R, Pasha MA, Ibrahim A, et al. (2001) Occupational lead exposure and amino acid profiles and liver function tests in industrial workers. Int $\mathrm{J}$ Environ Health Res 11: 181-188.

20. Penninckx MJ (2002) An overview on glutathione in Saccharomyces versus non-conventional yeasts. FEMS Yeast Res 2: 295-305

21. Adamis PD, Mannarino SC, Eleutherio EC (2009) Glutathione and gamma-glutamyl transferases are involved in the formation of cadmium-glutathione complex. FEBS Lett 583: 1489-1492. 
22. Nawrot TS, Staessen JA, Roels HA, Munters E, Cuypers A, et al. (2010) Cadmium exposure in the population: From health risks to strategies of prevention. Biometals 23: 769782.

23. Kim SJ, Han SW, Lee DJ, Kim KM, Joo NS (2014) Higher serum heavy metal may be related with higher serum gamma-glutamyltransferase concentration in Koreans: Analysis of the fifth Korea National Health and Nutrition Examination Survey (KNHANES V-1, 2, 2010, 2011). Korean J Fam Med 35: $74-80$.

24. Cederbaum Al (2001) Introduction-serial review: Alcohol, oxidative stress and cell injury. Free Radic Biol Med 31: 1524-1526.
25. Karp DR, Shimooku K, Lipsky PE (2001) Expression of gamma-glutamyl transpeptidase protects ramos B cells from oxidation-induced cell death. J Biol Chem 276: 37983804.

26. Volco M, Morris H, Cronin MT (2005) Metals, toxicity and oxidative stress. Curr Med Chem 12: 1161-1208.

27. Mallaro E, Dominici S, Del Bello B, Valentini MA, Pieri L, et al. (2000) Membrane gamma-glutamyl transpeptidase activity of melanoma cells: Effects on cellular $\mathrm{H}(2) \mathrm{O}(2)$ production, cell surface protein thiol oxidation and NF-kappa B activation status. J Cell Sci 113: 2671-2678.

28. Nazar SH, Salah ZA, Hanaa HH (2012) Contamination of heavy metals (lead, zinc, magnesium and manganese) concentration in Human Eyes. AJAC 3: 491-494. 